Cómo citar: J. Rivera, “Editorial. Desafíos para la ingeniería frente a la publicación de artículos derivados de los procesos de e investigación en educación superior", Inventum, vol. 16, no. 30, pp. 1-2. doi: 10.26620/uniminuto. inventum.16.30.2021.1-2

Editorial: Corporación Universitaria Minuto de Dios - UNIMINUTO.

ISSN: $1909-2520$

eISSN: $2590-8219$

Conflicto de intereses: los autores han declarado que no existen intereses en competencia.
EDITORIAL

\section{DESAFÍOS PARA LA INGENIERÍA FRENTE A LA PUBLICACIÓN DE ARTÍCULOS DERIVADOS DE LOS PROCESOS DE E INVESTIGACIÓN EN EDUCACIÓN SUPERIOR}

La situación actual de confinamiento ha resignificado el papel de la educación superior, con el fin de generar procesos de sostenibilidad y responder a los desafíos de los tiempos venideros en lo que compete a la función sustantiva desde la docencia, la investigación y la proyección social. En este orden de ideas, no se puede dejar de lado el papel fundamental de las ciencias, las ingenierías y las tecnologías como instrumentos al servicio de las personas, a través de los cuales se posibiliten procesos de transformación y apoyo acordes con las necesidades de las diferentes comunidades, mediante un modelo de resolución de problemas donde se generen proyectos de investigación que permitan vislumbras el reflejo de los mismos a través de la circulación del conocimiento por medio de publicaciones científicas en revistas especializadas

El número 30 de la revista Inventum de la Facultad de Ingeniería de la Corporación Universitaria Minuto de Dios - UNIMINUTO desde los campos de hábitat, productividad, ciencias básicas y convergencia digital publica siete artículos externos de carácter nacional y uno de carácter internacional, los cuales reflejan aportes y avances al desarrollo social, ambiental y tecnológico.

El primero de ellos plantea el desafío actual que tiene la educación superior en tiempos pandemia y pospandemia frente al proceso de enseñanza y aprendizaje por parte de docentes y estudiantes. Nos invita a repensar el proceso de cada uno de los actores de la comunidad educativa, la transformación de paradigmas y la epistemología del profesor frente a su discurso científico y donde surgen cuestionamientos de sí, en esta etapa actual, es posible formular proyectos de investigación que coadyuven al mejoramiento de la calidad de la educación. Se plantean situaciones tales como ¿Qué viene después de la pandemia para la educación superior? ¿Cuál será el papel de los docentes y estudiantes al retomar los modelos presenciales? ¿Se deben reorientar los programas curriculares ante estas cuestiones?

Dentro de la publicación se encuentran cuatro artículos con enfoque ambiental los cuales se titulan: Análisis de las brechas existentes para el sector de los biocombustibles en Colombia; Efectos de la contaminación ambiental producida por el tránsito vehicular sobre la salud humana como una revisión de literatura; Análisis de variables que influyen en el desbordamiento del Río Frío del municipio de Campoalegre en el departamento del Huila (Colombia); y finalmente, Reducción de la concentración de cefalexina en solución acuosa por electrocoagulación con electrodos de grafito. Si bien cada uno de ellos se ocupa de un objeto 
de conocimiento diferente, convergen en lo que tiene que ver con la mitigación del impacto ambiental, ya sea causado por las acciones propias del hombre o por la instrumentación y el uso de tecnología, que deteriora los procesos de la naturaleza. El último artículo, más centrado en la ciencia pura, posibilita transformaciones en el ámbito de la medicina y la generación de productos farmacéuticos, utilizando técnicas analíticas para el proceso de reducción en la concentración del principio activo que permiten reducir los impactos en términos de concentración.

Finalmente, se presentan los artículos con sentido y apropiación de la ingeniería bajo un enfoque social, los cuales se titulan: Sostenibilidad financiera de los sistemas estructurales de muros de carga y mampostería en proyectos de interés social; propuesta para la reducción de tiempos y productos no conformes en el área de confecciones de la empresa Suramericana de Guantes S. A. S. mediante herramientas de lean manufacturing, y finalmente, analiza las estrategias de mejora de la calidad de información en las órdenes de servicio de control pérdidas de energía.

En el primero, se brinda a las comunidades de bajos recursos alternativas de solución económica para la adquisición de vivienda a partir de una mirada holística de diferentes ingenieros que realizan el proceso y ponen de manifiesto la utilización de nuevos materiales, analizados y caracterizados fisicoquímicamente. El segundo, presenta una propuesta enfocada en la problemática de esta empresa, dedicada a la confección de dotaciones y prendas textiles bajo pedido, en la cual hay un bajo rendimiento productivo a causa de tiempos de ciclo muy altos y muchos reprocesos, lo cual genera incumplimiento en pedidos y altos costos de producción. Para tal fin, los investigadores proponen un desarrollo centrado en el análisis, la mediación y organización de los tiempos de cada referencia, la organización por familias de productos, el análisis de cada parte que permita reducir tiempos y disminuir la tasa de presentación de productos no conformes. El último artículo se encuentra encaminado hacia la sistematización y la clasificación de las diferentes variables que inciden en su desarrollo, para orientar la toma de decisiones en las organizaciones.

En correspondencia con lo anterior, es oportuno señalar que los procesos investigativos deben ser apoyados por todas las instancias educativas, las cuales deben atender a las dinámicas que en la actualidad se presentan en los diferentes contextos. En particular, en los tiempo actuales, se debe brindar el apoyo permanente a las ciencias, las ingenierías y las tecnologías, las cuales están llamadas a impulsar transformaciones en diferentes sectores empresarial, social, educativo, ambiental y tecnológico con el fin de promover el desarrollo de la sociedad colombiana y la circulación del conocimiento científico a través de publicaciones científicas seriadas, como la revista Inventum.

Julio César Rivera Rodríguez

Editor 